\title{
The central amygdala projection to the substantia nigra reflects prediction error information in appetitive conditioning
}

\author{
Hongjoo J. Lee, ${ }^{1,3}$ Michela Gallagher, ${ }^{2}$ and Peter C. Holland ${ }^{2}$ \\ ${ }^{1}$ Department of Psychology, The University of Texas at Austin, Austin, Texas 78712, USA; ${ }^{2}$ Department of Psychological and Brain \\ Sciences, Johns Hopkins University, Baltimore, Maryland 21218, USA
}

\begin{abstract}
The central amygdala nucleus ( $\mathrm{CeA}$ ) plays a critical role in cognitive processes beyond fear conditioning. For example, intact $\mathrm{CeA}$ function is essential for enhancing attention to conditioned stimuli (CSs). Furthermore, this enhanced attention depends on the CeA's connections to the nigrostriatal system. In the current study, we examined the role of the CeA's connections to two midbrain dopamine regions, the substantia nigra pars compacta (SNc) and the ventral tegmental area (VTA), in processing CS information when predictions of reward or nonreward were confirmed or disconfirmed. Initially, two different retrograde tracers were injected into the SNc and the VTA of rats, to label CeA cells. Different groups of rats then received a visual CS either paired or unpaired with food. Finally, Fos induction was assessed after a test session in which rats were exposed to the visual CS alone or paired with food. Colabeling of Fos and the retrograde tracer(s) showed that CeA neurons projecting to the SNc, but not to the VTA, were engaged in processing CS information when the training and testing conditions differed. These results suggest that the $\mathrm{CeA}$-nigral pathway represents prediction error information during appetitive conditioning.
\end{abstract}

The central amygdala nucleus (CeA) is best known for its role in mediating conditioned fear (Davis 2000). However, emerging evidence shows that the CeA also plays a critical role in other cognitive processes (Robledo et al. 1996; Holland and Gallagher 1999, 2003; Parkinson et al. 2000; Cardinal et al. 2002; Everitt et al. 2003; Corbit and Balleine 2005; Holland and Maddux 2010), including the acquisition of conditioned orienting responses (ORs) to stimuli paired with food. Novel stimuli grab the animals' attention and elicit unconditioned ORs, which may include both autonomic and motor components (Holland 1977; Kapp et al. 1979; Hunt and Campbell 1997). These ORs typically habituate if a stimulus is presented repeatedly without significant consequences, but may be maintained if the stimulus is paired with biologically significant events such as food or shock, perhaps reflecting top-down modulation of attention.

In a Pavlovian conditioning task in which a light cue is paired with food delivery, intact rats acquire both conditioned ORs (rearing) and conditioned food-cup approach responses. By contrast, rats with CeA lesions fail to acquire conditioned ORs, but display normal conditioned food-cup responses and unconditioned ORs (Gallagher et al. 1990). Studies of the effects of disconnection lesions showed that the acquisition and expression of conditioned ORs involves a circuit that includes the CeA, the substantia nigra pars compacta (SNc), and the dorsolateral striatum (Han et al. 1997; Lee et al. 2005).

Lee et al. (2005) examined the function of direct projections from CeA to SNc by combining anatomical tracing and neuronal activation detection methods. After injections of a retrograde tracer into the SNc, rats received light-food training, followed by a brief test with light alone. The rats' brains were then assessed for expression of Fos, the protein product of the immediate early

${ }^{3}$ Corresponding author.

E-mail leehj@psy.utexas.edu; fax (512) 471-6175.

Article is online at http://www.learnmem.org/cgi/doi/10.1101//m.1889510. gene $c$-fos, a common marker for neuronal activation (Sagar et al. 1988). Conditioning-dependent Fos expression was observed in the medial CeA: Rats with more training showed more Fospositive cells in the CeA than rats that received less training, or unpaired light and food presentations. Furthermore, the majority of Fos-positive cells in the CeA were labeled with retrograde tracer, showing that CeA cells that projected to SNc played an important role in processing cue information.

Lee et al. (2005) interpreted this Fos activation as directly indexing the associative or prediction strength of the light cue. Alternatively, it may have reflected processing of reward prediction error induced by omission of the expected food reward in test. This interpretation is plausible because Lee et al. $(2006,2008)$ found that CeA-SNc circuitry is also critical for the enhancement of learning that is often induced by surprising omission of an expected event. Here, we evaluated the role of CeA in processing reward prediction vs. prediction error information, by assessing Fos induced in tests with light-alone or light-food pairings, after extensive paired or explicitly unpaired presentations of light and food. In addition to assessing overall Fos expression in CeA, we also examined the separate contributions of CeA neurons that projected uniquely to $\mathrm{SNc}$ or to the ventral tegmental area (VTA), another midbrain dopamine area known to be important for processing reward prediction error information (Schultz et al. 1997).

Before behavioral training, each rat received injections of two different retrograde tracers into the SNc and the VTA to label CeA cells that project to these midbrain dopamine areas. Then, rats received extensive light-food pairings or unpaired presentations of light and food. Finally, Fos induction was assessed after different subgroups of rats in each training condition were tested with the visual cue alone or to the visual cue paired with food. Colabeling of Fos and the retrograde tracer(s) in the CeA was examined to understand the role of CeA projections to these midbrain dopamine areas in information processing. 

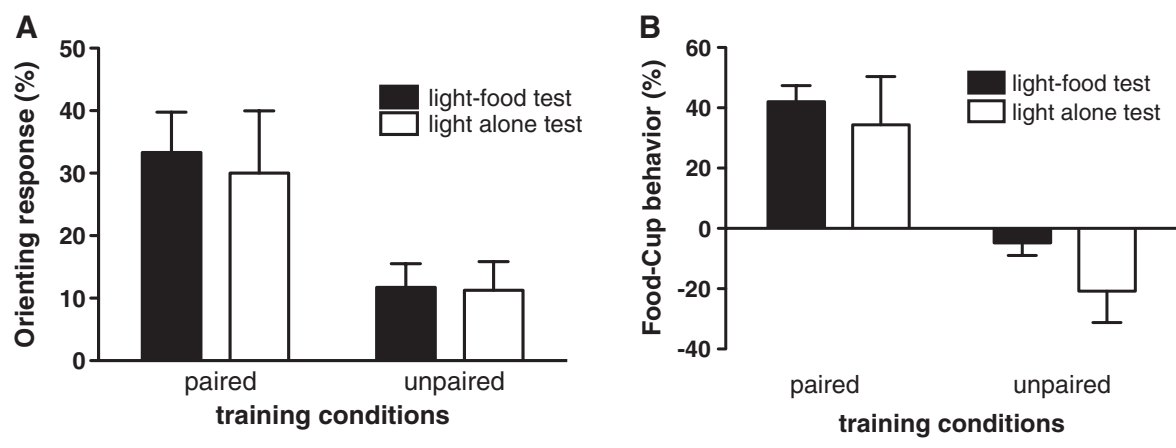

Figure 1. Mean $( \pm$ SEM) orienting response $(A)$ and food-cup response $(B)$ during the test session. The Paired group showed greater orienting response and food-cup behavior than the Unpaired group regardless of the test conditions. Black bars show the response levels of animals tested with light-food paired and the white bars show the response levels of animals tested with light alone.

\section{Results}

\section{Behavior}

During the training sessions, rats in the Paired group acquired both conditioned ORs and food-cup responses, relative to the Unpaired control rats (data not shown). A $2 \times 2 \times 8$ training $\times$ test $\times$ session repeated-measures ANOVA conducted on each response measure showed a significant main effect of training condition for both conditioned ORs, $F_{(1,23)}=5.41, P \leq 0.05$, and food-cup responses, $F_{(1,23)}=51.2, P \leq 0.0001$, as well as a training condition $\times$ sessions interaction, $F_{(7,161)}=3.30 P \leq 0.01$ and $F_{(7,161)}=19.68, P \leq 0.001$, respectively. Figure 1 shows behavioral responses during the test sessions in which the light CS was presented four times, either with food delivery (light-food) or alone (light alone). Rats in the Paired group continued to display conditioned ORs (Fig. 1A) and food-cup responses (Fig. 1B) regardless of the test conditions. Rats in the Unpaired group did not show significantly more responding during the light than during pre-CS (baseline) periods, regardless of test condition. A $2 \times 2$ training $\times$ test ANOVA showed significant main effects of training conditions for both conditioned ORs, $F_{(1,23)}=9.52, P \leq 0.01$, and foodcup responses, $F_{(1,23)}=36.70, P \leq 0.001$. Neither the main effects of test condition, $F_{(1,23)}=0.08, P \geq 0.1$ for ORs, $F_{(1,23)}=1.98, P \geq$ 0.1 for food-cup responses, nor the training $\times$ test interactions, $F_{(1,23)}=0.05, P \geq 0.1$ and $F_{(1,23)}=0.25, P \geq 0.1$, respectively, were significant.

\section{Fos expression in the $\mathrm{CeA}$}

Figure 2 shows photomicrographs of CeA stained for Fos-positive cells (Fig. 2A) and the mean numbers of Fos-positive cells in the medial nucleus (Fig. 2B, left panel) and the lateral nucleus (Fig. 2B, right panel) of the CeA. Overall, considerably more Fos-positive cells were observed in the medial CeA than in the lateral CeA. Consider first the data from medial CeA. Rats in the Paired group expressed similar levels of Fos, regardless of the test conditions. In contrast, the rats in the Unpaired group showed higher levels of Fos expression when they were tested with light followed by food than when they were tested with light alone. Confirming these observations, ANOVA showed a significant training $\times$ test interaction, $F_{(1,23)}=5.81, P \leq 0.05$, and a main effect of test condition, $F_{(1,23)}=7.46, P \leq 0.05$. In addition, Unpaired rats tested with light-food showed significantly more responding than Unpaired rats tested with light alone, $P<0.05$.

\section{Colocalization of Fos with retrogradely labeled cells}

Injections of two different retrograde tracers (FG and CTb) into the SNc and VTA were used to identify the CeA neurons that project to these two regions. Figure 3 shows the location of the injection sites in SNc and VTA, and the retrogradely labeled cells in CeA. In agreement with previous studies (Wallace et al. 1992; Zahm et al. 1999), there was very light labeling of CeA neurons after retrograde tracer injection into VTA, but substantial labeling of CeA neurons after retrograde tracer injection into SNc (Bunney and Aghajanian 1976; Swanson 1982; Gonzales and Chesselet 1990; Fudge and Haber 2000; Lee et al. 2005).

An additional set of brain sections containing CeA was stained with three different fluorophores to visualize neurons positive for Fos, FG, and CTb in the same section. Figure $4 \mathrm{~A}$ is a photomicrograph showing CeA neurons positive for Fos, FG, and CTb. Counting of Fos-positive neurons visualized with a fluorophore revealed similar results (Fig. 4B) as the counting of Fos-positive neurons via peroxidase-based staining (Fig. 2B, left panel). In agreement with that analysis of Fos expression, there was a significant training $\times$ test interaction, $F_{(1,15)}=$ $10.72, P \leq 0.01$, and a main effect of test condition, $F_{(1,15)}=$ $8.67, P=0.01$. Individual comparisons showed that Fos expression in the Unpaired light-alone condition was significantly lower than in any other condition, $P \mathrm{~s}<0.05$.

Figure $4 \mathrm{C}$ shows the primary data of this experiment: the mean numbers of cells positive for both Fos and retrograde tracers after the tracers were injected into the SNc. This colabeling indicates the numbers of SNc-projecting medial CeA cells that were activated in the various test conditions. Colabeling of Fos and retrograde tracers occurred most in rats that received different training and test conditions (i.e., testing with light alone after Paired training, and testing with light-food after Unpaired training). Rats in the Paired light-food condition showed less colabeling than either of those two groups, despite comparable Fos levels among those groups when all CeA cells, not just those that project to the SNc, were considered (Fig. 4B). Finally, few SNc-projecting neurons were Fos-positive in the Unpaired lightalone condition.

These impressions were supported statistically. An initial analysis showed that colabeling of Fos and retrograde tracer did not differ as a function of the tracer used (FG vs. CTb) or the injection side (left vs. right hemisphere), so we collapsed across those variables for subsequent analyses. A training $\times$ test ANOVA showed a significant interaction between training and test conditions, $F_{(1,15)}=20.88, P \leq 0.0005$. Individual comparisons showed that colabeling in the Unpaired light-alone condition was significantly lower than the Unpaired light-food condition and the Paired light-alone condition $(P \mathrm{~s}<0.05)$, but not the Paired light-food condition.

When the colabeled cells were calculated as a percentage of total Fos-positive cells (Table 1, left columns), similar trends emerged. Among rats in the Paired training condition, the majority of the Fos-positive cells were also retrogradely labeled cells in the light-alone test condition, while a lower percentage of colabeling of Fos and the retrograde tracer was observed in the lightfood test condition. By contrast, in the Unpaired group, the rats that were tested with light followed by food showed a higher percentage of colabeling of Fos-positive cells and the retrograde tracer, compared with the rats tested with light alone. As with the absolute cell numbers, a training $\times$ test ANOVA showed a significant interaction between training and test conditions, $F_{(1,15)}=5.82, P \leq 0.05$. Finally, when the colabeled cells were 
A

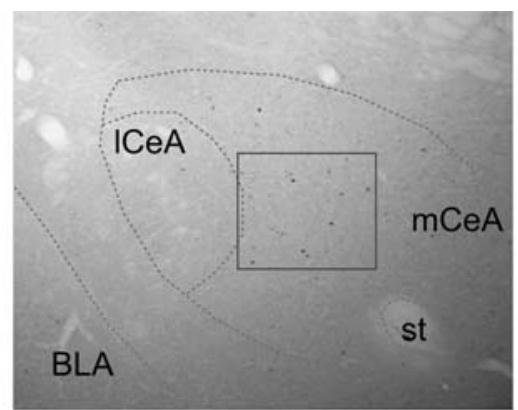

medial CeA

B

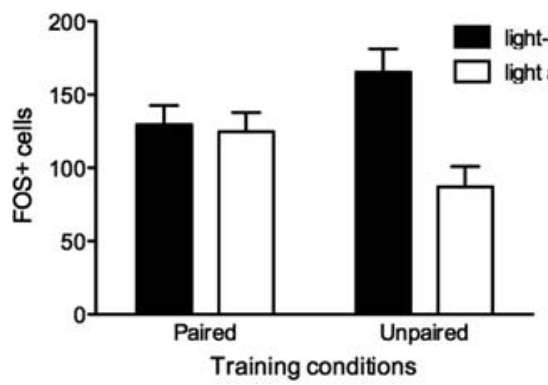

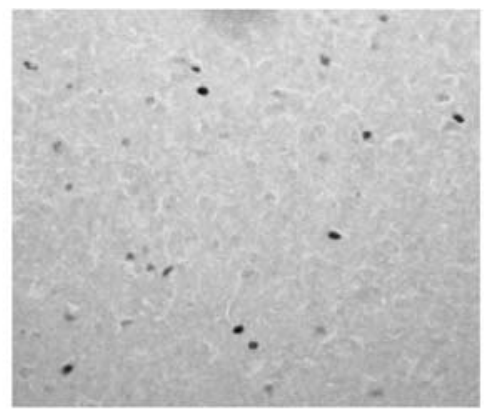

lateral $\mathrm{CeA}$

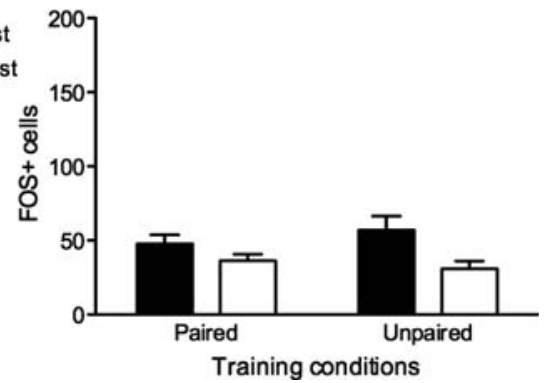

Figure 2. (A) Photomicrographs of the CeA in the immunohistochemically processed tissue for Fos following the test session. Fos-positive cells are mostly seen in the medial (mCeA) nuclei of the CeA (left panel). The rectangular area is shown at higher magnification in the right panel. BLA, basolateral amygdala; ICeA, lateral CeA; st, stria terminalis. $(B)$ Mean $( \pm$ SEM) numbers of Fos-positive cells in the medial (left panel) and the lateral (right panel) CeA. In the medial CeA, similar levels of Fos-positive cells were observed in the Paired group regardless of the test conditions, whereas higher levels of Fos-positive cells were seen in the Unpaired group tested with light followed by food instead of light alone. In the lateral CeA, higher levels of Fos expression were seen when the animals were tested with light and food instead of light alone, regardless of the training conditions. By contrast, in lateral $\mathrm{CeA}$, rats that were tested with light followed by food showed higher levels of Fos expression than rats tested with light alone, regardless of training condition. In support of these observations, ANOVA showed a main effect of test, $F_{(1,23)}=5.93, P \leq 0.05$, but no significant effect of training, $F_{(1,23)}=0.06, P=0.80$, or training $\times$ test interaction, $F_{(1,23)}=0.87, P=0.36$.

considered as a proportion of all the retrogradely labeled cells in the CeA, similar trends also emerged, even though these proportions were quite low (Table 1 , right columns). A training $\times$ test ANOVA again showed a significant interaction between training and test conditions, $F_{(1,15)}=10.28, P \leq 0.01$.

In contrast to the colocalization of Fos and retrograde tracer in the CeA after tracer injections into SNc, there was very little colabeling of Fos-positive cells with retrograde tracer in CeA after injections into VTA, regardless of the training or test conditions (Fig. 4D and Table 1), Fs $<1$. Thus, VTA-projecting neurons in the medial CeA played little role in test performance.

Finally, there was only minimal labeling by all three of Fos, FG, and CTb. The mean number of triple-labeled cells ranged from 0.5 to 2.1 among the groups, with no significant between-group differences. This observation is consistent with prior observations that relatively few CeA neurons project to both SNc and VTA.

\section{Discussion}

Consistent with previous studies (Gonzales and Chesselet 1990; Lee et al. 2005), retrograde tracing identified heavy projections from the medial CeA neurons to the SNc. These SNc-projecting neurons showed greater Fos expression when outcome expectancies established in training were violated in test. Both rats that received surprising omission of food (light-alone test of Paired rats) and rats that received surprising presentation of food (light-food test of Unpaired rats) showed greater percentage of double-labeling of Fos and tracer in the medial CeA than rats receiving expected presentation of food (light-food test of Paired rats) or expected absence of food (light-alone test of Unpaired rats). By contrast, only a small proportion of medial CeA neurons were identified as projecting to VTA, and these neurons were not differentially responsive to treatment or test conditions. Finally, few if any neurons in lateral CeA projected to either midbrain region, and overall, neurons in lateral CeA showed less Fos activation than those in the medial CeA. Nevertheless, lateral CeA neurons showed greater Fos expression when the rats were tested with light-food pairings than when tested with light alone, regardless of training conditions, suggesting that those neurons were primarily responsive to food presentation.

Although the temporal resolution of intermediate early gene (IEG) methods alone does not permit distinguishing between signals produced by the cue itself (a reward prediction signal), the food (a reward signal), and those that occurred at cue termination (a rewardprediction error signal), the pattern of Fos expression observed here for medial CeA neurons that project to the $\mathrm{SNc}$ is not consistent with activation by the former two signals alone. For example, if these neurons responded to food and its prediction, then coexpression of Fos and tracer should have been highest in the Paired rats tested with light-food pairings. Similarly, if these neurons responded only to food, then the two groups tested with light-food should have both showed more Fos and tracer double-labeling than the two groups of rats tested with light alone. Even if the value of food was modulated by positive and/or negative predictions (e.g., Wagner 1978; Rescorla and Holland 1982) elsewhere in the brain, and that net value conveyed to CeA (thus, accounting for the greater coexpression of Fos and tracer observed after the light-food test in Unpaired rats than in Paired rats), one would still anticipate more double-labeling of Fos and tracer in Paired rats when the light was presented with food than when it was presented alone. Thus, although this study does not rule out additional contributions of food prediction and food presentation (as was likely in lateral CeA neurons) to Fos expression in this subset of CeA neurons, only a responsiveness based on violation of learned expectations accounts for the pattern of data observed here. A similar activation occurred in the case of negative prediction error, when expected food was omitted, and in the case of positive prediction error, when unexpected food occurred. These results suggest that activity in the CeA-nigral pathway may signify processing of unsigned prediction error information during associative learning. Of course, our methods cannot distinguish between processing of prediction error information itself in the CeA and its representation of some consequence of that information. For example, CeA activity might reflect some downstream emotional or attentional manifestation of surprise resulting from prediction error computed elsewhere. 
A
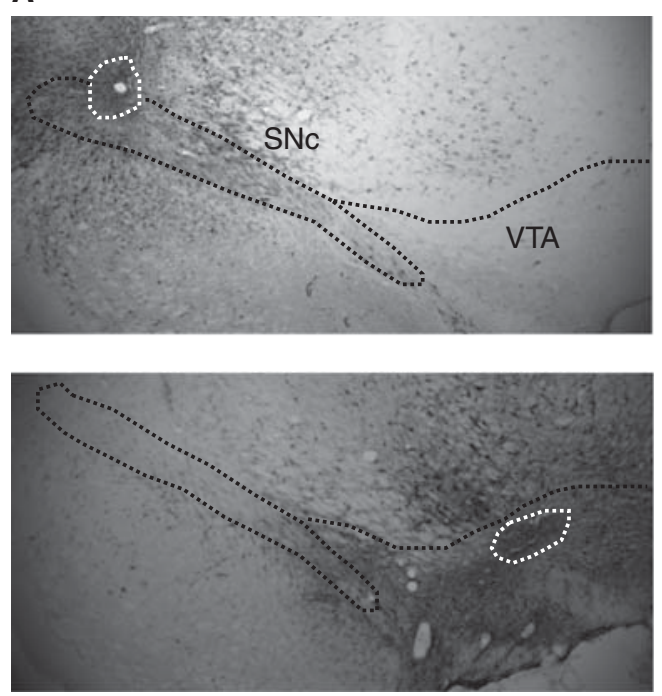

B
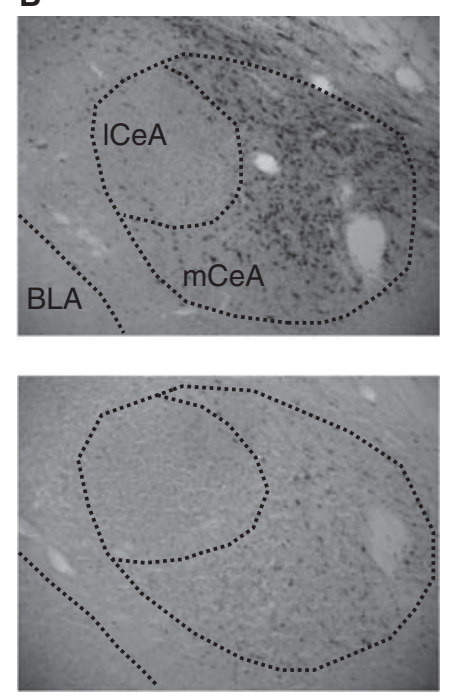

C

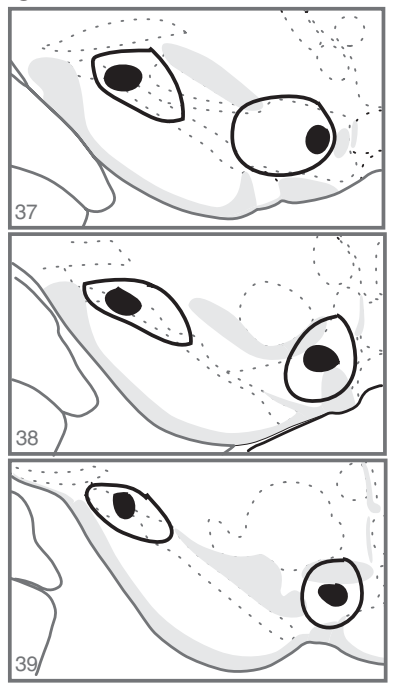

Figure 3. (A) Photomicrographs of the SNc and the VTA in the immunohistochemically stained tissue for FG, taken from two different animals (S-1 and S-2). The white dotted line encircles the area of the FG deposit within the SNc and the VTA. (B) Photomicrographs of the CeA in the immunohistochemically stained tissue for FG, taken from the same animals shown in $A$. There is a heavy retrograde labeling in the CeA after FG injection into the SNc, but only light labeling in the CeA after FG injection into the VTA. Also, labeling is seen mainly in the medial CeA and not in the lateral CeA. (C) Depiction showing the extent of the smallest (filled area) and the largest (enclosed area) FG deposit in the SNc and the VTA. Plates were adapted from the Swanson (1992) atlas and reprinted with permission from Elsevier (c) 1992.

Other studies from our laboratories also indicated that the CeA-SNc pathway is important for processing or using negative prediction error information when an expected event is omitted (Lee et al. 2006, 2008). After extensive exposure to a light $\rightarrow$ tone sequence, normal rats learned light-food associations in a test phase more rapidly if light-alone exposures intervened between training and test than if they received additional light-tone exposure, as if the surprising omission of the tone enhanced attention to the light (Pearce and Hall 1980; Wilson et al. 1992). No such enhancement was observed in rats with either permanent or transient disconnection of the CeA-SNc pathway. Furthermore, using the same training procedures, Bucci and MacLeod (2007) found more Fos expression in the CeA of rats that were evaluated after the light-alone presentations than in rats sacrificed after lighttone presentations, reminiscent of our present observations with omission or presentation of food in the Paired rats. Finally, it is notable that the SNc is highly interconnected with neurons in the basal forebrain substantia innominata, which are also known to play an important role in the expression of these surprise-induced enhancements of attention (Chiba et al. 1995; Bucci et al. 1998; Holland and Gallagher 2006).

Schultz and colleagues (1997) have stressed the role of midbrain DA cells in prediction error, including examples of negative prediction error. They reported decreased activation of midbrain DA cells in monkeys when predicted rewards were omitted. Although Matsumoto and Hikosaka (2007) implicated the lateral habenula in the inhibition of DA neuron firing with reward omission, CeA-SNc connections may also provide an important source of regulation. Many known outputs of the CeA are GABAergic (Pitkanen and Amaral 1994; Jia et al. 1997; Swanson and Petrovich 1998; Cassell et al. 1999; Saha et al. 2000). Although it is not clear whether CeA projections to the SNc are GABAergic, if that were the case, then increased CeA activity, when predicted reward is omitted, might dampen DA neuron activity in the SNc. Lesions or inactivation of the CeA then should block this normal dampening of activity of the SNc DA neurons under conditions of negative prediction error. Reciprocal connections from the SNc to the CeA could also play a role. Destroying nigral DA cells results in significantly reduced dopamine fibers in the CeA (von Bohlen Und Halbach et al. 2005). That DA innervation, densely terminating in the region of CeA where GABAergic neurons predominate, makes synaptic contact with CeA GABAergic cells (Freedman and Cassell 1994; Asan 1998). Recording of CeA neuron activity after SNc DA depletion or detecting Fos in CeA-projecting SNc DA neurons may illuminate whether the reciprocal connections are important for processing negative prediction error information.

The present data also suggest a role for CeA-SNc circuitry in processing positive prediction error information, when unexpected reward is presented. Rats in the Unpaired condition that received unexpected food delivery in test $(\mathrm{UP}+)$ showed more Fos expression in SNc-projecting medial CeA neurons than rats in the Paired condition that received expected food delivery $(\mathrm{P}+)$. On the surface, this observation is inconsistent with our suggestion that negative prediction error involves suppression of DA neuron activity by GABAergic projections from CeA: Delivery of unexpected reward is typically accompanied by increased activation of DA cells (Schultz et al. 1997). However, it is notable that the CeA is enriched with many peptides (Cassell et al. 1999), and it is possible that different sets of SNc-projecting cells with different chemical properties are responsive to positive and negative prediction error information. The combination of our techniques with assays of neurochemical phenotype might shed light on this speculation.

Unlike with aspects of processing negative prediction error information, which has been shown to depend on intact CeA function in a number of behavioral tasks (Holland and Gallagher 1993a,b; Holland et al. 2001; Holland and Kenmuir 2005; Holland 2006; Haney et al. 2010), we found no behavioral effects of bilateral CeA lesions (Holland and Gallagher 1993a; Holland 2006) in studies of enhanced attention induced by unexpected presentation of an additional reward on a conditioning trial. Thus, although positive prediction error information may 
A

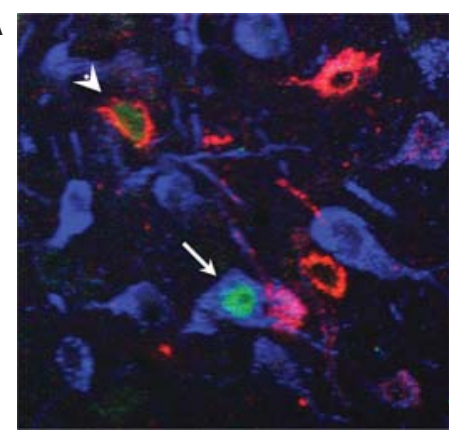

C

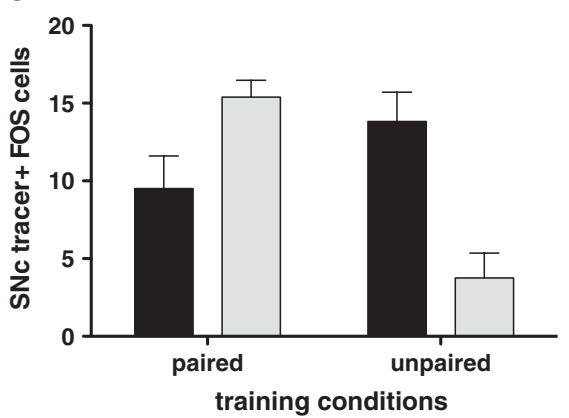

B

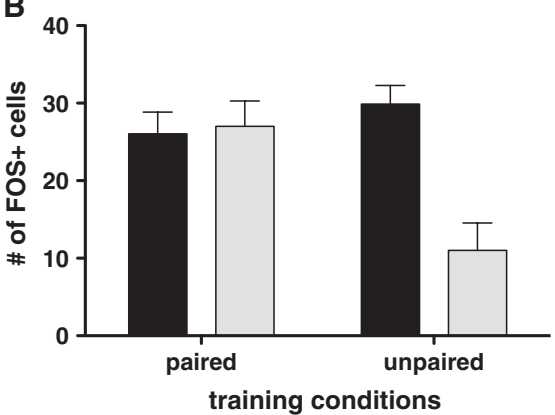

D

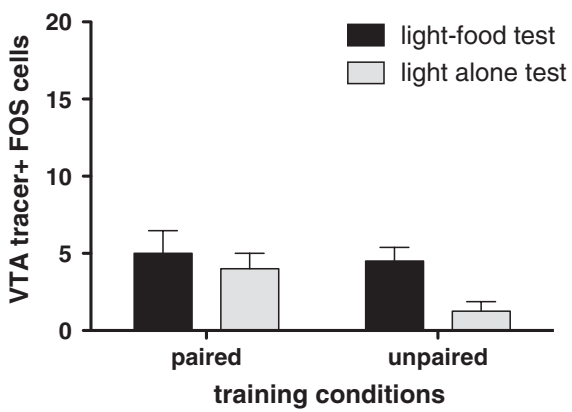

Figure 4. (A) A photomicrograph of the medial CeA neurons in the immunofluorescence-labeled tissue for Fos (green), FG (blue), and CTb (red) after FG and CTb injections to the SNc and the VTA, respectively. It shows one cell (arrow) coexpressing Fos and FG, and another cell (arrowhead) coexpressing Fos and CTb. (B) Mean ( \pm SEM) number of Fos-positive cells in the medial CeA processed for immunofluorescent labeling of Fos and retrograde tracers. $(C, D)$ Mean $( \pm S E M)$ number of colabeling of Fos-positive and retrogradely labeled cells in the medial CeA after retrograde tracer injection to the $\mathrm{SNc}(C)$ and to the VTA (D).

be represented in CeA, CeA function may not be critical to the use of that information in a number of experimental contexts.

Many discussions of roles of midbrain DA neurons in reward prediction error emphasize the VTA. Consistent with other reports (Zahm et al. 1999; Kaufling et al. 2009), our results showed that direct projections from CeA to VTA are sparse, and that very few CeA cells projecting to the VTA were activated in our behavioral paradigm. However, these observations do not rule out interactions between CeA and VTA in processing prediction error information. Such interactions could involve indirect pathways, for example, via the lateral hypothalamus (Fadel and Deutch 2002; Leinninger et al. 2009). As noted in the case of SNc, the VTA may also influence CeA activity. In the current study, the lateral CeA of rats that were tested with light + food showed higher levels of Fos expression than rats that were tested with light alone, regardless of the training conditions. Given that the lateral CeA

Table 1. Percentage of colabeled cells

\begin{tabular}{llllll}
\hline & \multicolumn{2}{c}{$\begin{array}{c}\text { Colabeled cells/ } \\
\text { Fos+ cells (\%) }\end{array}$} & & \multicolumn{2}{c}{$\begin{array}{c}\text { Colabeled cells/ } \\
\text { tracer+cells (\%) }\end{array}$} \\
\cline { 2 - 3 } \cline { 6 - 7 } & SNc & VTA & & SNc & VTA \\
\hline $\mathbf{P}+$ & $39.2 \pm 11.1$ & $18.3 \pm 5.2$ & & $7.8 \pm 1.5$ & $7.1 \pm 1.6$ \\
$\mathbf{P}-$ & $59.8 \pm 6.3$ & $14.8 \pm 2.6$ & & $11.8 \pm 1.6$ & $5.9 \pm 0.6$ \\
UP+ & $45.5 \pm 4.1$ & $16.4 \pm 4.2$ & & $9.7 \pm 1.3$ & $6.9 \pm 1.8$ \\
UP- & $30.5 \pm 8.9$ & $12.1 \pm 4.3$ & & $3.6 \pm 1.9$ & $2.3 \pm 1.2$ \\
\hline
\end{tabular}

Percentage $( \pm$ SEM) of colabeled cells (i.e., Fos + and tracer +$)$ in relation to total number of Fos-positive cells (left two columns) and to total number of retrogradely labeled cells (right two columns). receives DA inputs from both the VTA and the SNc (Hasue and ShammahLagnado 2002), it is plausible that reward information is relayed from multiple midbrain DA areas to the lateral CeA. The current study is limited in addressing complex and intertwined relationships between the midbrain DA system and the amygdala in processing reward and prediction information. However, in combination with earlier studies (Lee et al. 2006, 2008), it demonstrates the importance of CeA-SNc circuitry in the processing of negative prediction error information.

Finally, CeA-SNc circuitry is also important for mediating conditioned orienting, which can be viewed as a behavioral manifestation of attention to cues that signal biologically significant events such as food. Lee et al. (2005) found that lesions disconnecting the $\mathrm{CeA}$ and the SNc blocked acquisition of conditioned orienting. From that perspective, one might have expected a substantial food prediction signal in SNcprojecting CeA neurons. However, the roles of CeA and $\mathrm{SNc}$ in conditioned orienting are time-limited; whereas $\mathrm{SNc}$ function is required for both their acquisition and expression (El-Amamy and Holland 2006), CeA function is critical only at the time of acquisition (McDannald et al. 2004) and not at the time of expression after extended training. Thus, CeA function in conditioned orienting is maximal when prediction error is high. For that reason, one might not expect a substantial food prediction signal to the light in CeA after extensive light-food training, as in the present experiment. All in all, the role of the CeA in appetitive conditioning, and of CeASNc connections in particular, might best be described as modulating attention to stimuli under conditions of uncertainty, for example, in the initial stages of associative learning when cueoutcome expectancies are not yet fully formed, and later when established expectancies are violated.

\section{Materials and Methods}

\section{Subjects}

Experimentally naïve, male Long-Evans rats (Charles River Laboratories, Raleigh, NC), initially weighing 300-350 g, were individually housed in a climate-controlled vivarium on a 12:12-h light/dark cycle (lights on at 07:00) with free access to water. They were fed ad libitum during acclimation and the postoperative recovery period. Starting $5 \mathrm{~d}$ prior to training until the completion of the study, they were placed on a restricted diet to maintain $85 \%$ of free-feeding body weight. All experiments including the surgery were conducted according to the National Institutes of Health's guide and protocols approved by the Johns Hopkins University Animal Care and Use Committee.

\section{Surgery}

Rats were anesthetized with isoflurane gas (Abbott Laboratories) and placed in a stereotaxic frame (Kopf Instruments). FluoroGold (FG) (Fluorochrome) and Cholera Toxin Subunit B (List Biological Laboratories) were used to label the CeA cells 
retrogradely from the SNc and the VTA. Half of the rats received unilateral injections of FG into the SNc and Cholera Toxin Subunit B (CTb) into the VTA in the same hemisphere, and the other half received unilateral injections of FG into the VTA and $\mathrm{CTb}$ into the SNc in the same hemisphere. The injection site was also balanced, such that there were equal numbers of rats with retrograde tracer injections in the left and the right $\mathrm{SNc}$ and VTA. FG was prepared in $0.9 \%$ sterile saline at a $4 \%$ concentration and $\mathrm{CTb}$ was prepared in distilled water at a $1 \%$ concentration. A volume of $0.1 \mu \mathrm{L}$ of each tracer was injected via a Hamilton microsyringe over a $2-3$-min period. The coordinates were measured from bregma: 5.3 posterior, 2.4 lateral, and 7.4 ventral for SNc and 5.0 posterior, 0.8 lateral, and 8.2 ventral for VTA. After surgery, all rats received a single subcutaneous injection of buprenorphine hydrochloride $(0.025 \mathrm{mg} / \mathrm{kg}$; Sigma) for amelioration of pain. Rats began behavioral training $15 \mathrm{~d}$ after surgery: $10 \mathrm{~d}$ for postoperative recovery and $5 \mathrm{~d}$ of acclimation period for food-restriction schedule.

\section{Apparatus}

The behavioral training apparatus consisted of four individual chambers $(22.9 \times 20.3 \times 20.3 \mathrm{~cm})$. Each chamber had aluminum front and back walls, clear acrylic sides and top, and a floor made of stainless steel rods $(0.48 \mathrm{~cm}$ in diameter spaced $1.9 \mathrm{~cm}$ apart $)$. A food cup, fitted with phototransistors for detecting head entries, was recessed in the center of the front wall $2 \mathrm{~cm}$ above the floor. A jeweled 6-W lamp, mounted on the front panel of the chamber, $15 \mathrm{~cm}$ above the food cup, served as the source of the visual cue. Each chamber was enclosed in a sound-attenuated box where constant dim illumination was provided by a $6-\mathrm{W}$ red light and ventilation fans provided masking noise (70 dB). A television camera was mounted within each box and images were recorded during behavioral training and testing.

\section{Behavioral procedures}

Rats received Pavlovian appetitive conditioning in which a light served as the conditioned stimulus (CS) and food served as the unconditioned stimulus (US). For conditioning, rats were divided into two groups: Paired $(n=14)$ and Unpaired $(n=13)$. Rats in the Unpaired group served as controls for conditioning. All rats were first trained to eat from the recessed food cup by delivering two 45-mg pellets (Research Diets), with intertrial intervals (ITIs) ranging from 2 to $6 \mathrm{~min}$, in each of two 64-min sessions. On the first day of conditioning (Day 1), all rats were given eight 10-sec light alone presentations $(2-6 \mathrm{~min}$ ITI) to habituate their unconditioned orienting responses to light. After the habituation session, rats in the Paired group received eight 10-sec light presentations (2-6 min ITI) followed immediately by the delivery of two food pellets. Rats in the Unpaired group received eight presentations of the 10-sec light and eight food deliveries, explicitly unpaired. Starting on Day 2, the Paired group received seven additional sessions of 16 light-food pairings, while the Unpaired group received seven sessions of 16 presentations of light and 16 food deliveries, explicitly unpaired. On the test day (Day 9), rats from each group were assigned to one of two different test conditions: Half of the rats received a light-food test session in which four 10 -sec light presentations were followed by food delivery while the other half received a light-alone test session in which four 10 -sec light-alone presentations were given. The test session was 16 min long. The number of rats in each combination of training and testing condition were: Paired conditioning with light-food test, $n=9$; Paired conditioning with light-alone test, $n=5$; Unpaired conditioning with light-food test, $n=8$; and Unpaired conditioning with light-alone test, $n=5$.

Behavioral observations were made from videotapes during the 5 -sec period immediately prior to light presentations and during the 10-sec period of light presentations. Observation for ORs was paced by auditory signals (1.25-sec intervals) recorded on the tapes. The OR to the light was defined as standing on the hind legs with both front legs off the floor, but not grooming, and was recorded using custom-written software with a keyboard button press. An observer who was blind to the experimental design recorded the orienting behavior. Food-cup behavior was indexed by the photocells in the recessed food cup and reported as the percentage of time spent in the food cup. In previous studies (Holland 1977, 1984), orienting and food-cup behaviors occurred primarily during the first 5-sec and the last 5-sec periods of CS presentations, respectively. Thus, in this study, ORs were reported only for the first 5-sec period and food-cup behaviors were reported for the last 5-sec period of light presentation. To reduce the contribution of within-group variation in baseline responding, we report the difference between CS responding and pre-CS responding (responding during the 5 -sec period prior to light presentation). Baseline responding did not differ among the groups during either conditioning or testing.

\section{Histology}

Rats were sacrificed $90 \mathrm{~min}$ after the beginning of the test session to detect Fos expression induced by light and/or food. Rats were deeply anesthetized with pentobarbital $(100 \mathrm{mg} / \mathrm{kg})$ and perfused with $0.9 \%$ saline followed by $4 \%$ paraformaldehyde in $0.1 \mathrm{M}$ phosphate buffer (PB). Brains were removed, post-fixed, and cryoprotected overnight in $4 \%$ paraformaldehyde in $0.1 \mathrm{M}$ $\mathrm{PB}$ containing $12 \%$ sucrose, and stored at $-80^{\circ} \mathrm{C}$. Brains were then sliced on a freezing microtome, and $30-\mu \mathrm{m}$ coronal sections through the CeA, SNc, and VTA were collected in four series.

\section{Immunohistochemistry}

The first series of sections was used for Fos immunohistochemical staining. The third series of sections was further divided into two sets, in which each set was used for FG and CTb staining. The second series of sections was stained for Nissl in order to verify anatomical locations of adjacent sections immunoreacted for Fos, FG, and CTb. Immunohistochemical staining for Fos, FG, and $\mathrm{CTb}$ followed a protocol simialr to that used by Lee et al. (2005). The primary antibodies used were: rabbit FG antibody (1:5000-10,000 dilution; Chemicon \#AB153), goat CTb antibody (1:5000-10,000 dilution; List Biological Laboratories \#703), and rabbit Fos antibody (1:5000 dilution; Santa Cruz Biotechnology $\#$ sc-52). After the primary antibody incubation $(48-72 \mathrm{~h}$ at $4{ }^{\circ} \mathrm{C}$ ), sections were rinsed in $0.1 \mathrm{M} \mathrm{PB}$ containing $0.9 \%$ saline (PBS), incubated in the appropriate biotinylated secondary antibodies such as goat antirabbit IgG or horse antigoat IgG (1:250 dilution; Vector Laboratories) for $1-1.5 \mathrm{~h}$, rinsed in PBS, and then incubated in avidin-biotin peroxidase conjugate (Vector laboratories) for $1-2 \mathrm{~h}$. After several rinses in PBS, sections were reacted using a Vector SG or DAB substrate kit for peroxidase (Vector Laboratories) in order to visualize Fos, FG, or CTb. Sections were mounted on slides, dehydrated in ascending concentrations of alcohol, and coverslipped with Permount.

\section{FG, CTb, and Fos triple-immunofluorescent labeling}

The fourth series of sections was used to examine colocalization of FG, CTb, and Fos in the CeA. Free-floating tissues were preincubated for $1 \mathrm{~h}$ in a blocking solution (i.e., 3\% normal donkey serum in $0.1 \mathrm{M}$ PBS with $0.3 \%$ Triton). Sections were then incubated in the blocking solution containing both rabbit Fos antibody (1:500, Santa Cruz Biotechnology) and goat CTb antibody (1:1,000, List Biological Laboratories) for $72 \mathrm{~h}$ at $4^{\circ} \mathrm{C}$. After several rinses in PBS, sections were incubated in the blocking solution with the addition of donkey anti-rabbit IgG-Alexa 488 (1:300; Molecular Probes) and donkey anti-goat IgG-Alexa 546 (1:300; Molecular Probes) for $1.5 \mathrm{~h}$. After several rinses in PBS, sections were incubated in the blocking solution containing rabbit FG antibody (1:500; Chemicon) for $24 \mathrm{~h}$ at $4^{\circ} \mathrm{C}$. The sections were again rinsed in PBS, incubated in blocking solution containing donkey anti-rabbit IgG-Cy5 (1:150; Jackson ImmunoResearch Laboratories) for $1.5 \mathrm{~h}$, and rinsed in PBS. Sections were then mounted onto slides, coverslipped with Vectashield hardset mounting medium with DAPI (Vector Laboratories), and stored in the dark at $4^{\circ} \mathrm{C}$. 


\section{Analysis of Fos expression}

Analyses were conducted blind with respect to training condition and the tracer injection site. Medial and lateral subnuclei of CeA were defined according to Swanson's Rat Brain Atlas (Swanson 1992). Three sections from different rostral-caudal levels (levels 25 to 27 according to Swanson 1992) and two sections from levels 27 to 28 were used to analyze bilateral medial and lateral CeA, respectively. Images of the Fos -stained sections and the adjacent thionin-stained sections were acquired using a MicroPublisher RTV camera (QImaging). Borders of the medial and lateral CeA were then drawn on the images of Fos sections, guided by the thionin-stained sections, using Adobe Photoshop. Using an image analysis system (NIH Image 1.63), a threshold for background density was set for each medial and lateral CeA regions on the Fos section, and Fos -positive cells with a density that was at least two standard deviations above the background threshold were counted using the software. There were no hemisphere or injection site differences in Fos levels. Thus, the total counts of Fos -positive cells from both CeAs were averaged for analysis.

\section{Analysis of FG, CTb, and Fos colocalization}

Sections labeled with immunofluorescence for FG, CTb, and Fos were analyzed by confocal microscopy (Carl Zeiss Laser Scanning System LSM 510). Sections from levels 25 to 27 were selected and the medial CeA ipsilateral to the tracer injection sites was examined. The nuclear counterstain DAPI was used as a visual guide to locate the medial CeA and at least two image samples from each section (average of 6-7 samples per animal) were collected. Using a $40 \times$ oil-immersion objective, all images were captured through the Z-plane. A typical image sample had about 22 Z-stacks of $1-\mu \mathrm{m}$ optical sections. Using Zeiss LSM ImageBrowser software, each optical section was examined and cells positive for each of FG, CTb, and Fos were counted independently. This method ensured that only entire neurons were included in the analysis (i.e., presence of $80 \%$ cell bodies in all $\mathrm{X}-$, $\mathrm{Y}-$-, and Z-planes). Furthermore, cells coexpressing FG, CTb, and/or Fos were counted with a full evaluation through Z-planed sections.

\section{Statistical analysis}

For all analyses, group comparisons were made using a $2 \times 2$ training (Paired vs. Unpaired) $\times$ test (light-food vs. light alone) factorial ANOVA, with Bonferroni tests for post-hoc comparisons, when appropriate.

\section{References}

Asan E. 1998. The catecholaminergic innervation of the rat amygdala. Adv Anat Embryol Cell Biol 142: 1-118.

Bucci DJ, Macleod JE. 2007. Changes in neural activity associated with a surprising change in the predictive validity of a conditioned stimulus. Eur J Neurosci 26: 2669-2676.

Bucci DJ, Holland PC, Gallagher M. 1998. Removal of cholinergic input to rat posterior parietal cortex disrupts incremental processing of conditioned stimuli. J Neurosci 18: 8038-8046.

Bunney BS, Aghajanian GK. 1976. The precise localization of nigral afferents in the rat as determined by a retrograde tracing technique. Brain Res 117: 423-435.

Cardinal RN, Parkinson JA, Lachenal G, Halkerston KM, Rudarakanchana N, Hall J, Morrison CH, Howes SR, Robbins TW, Everitt BJ. 2002. Effects of selective excitotoxic lesions of the nucleus accumbens core, anterior cingulate cortex, and central nucleus of the amygdala on autoshaping performance in rats. Behav Neurosci 116: $553-567$.

Cassell MD, Freedman LJ, Shi C. 1999. The intrinsic organization of the central extended amygdala. Ann N Y Acad Sci 877: 217-241.

Chiba AA, Bucci DJ, Holland PC, Gallagher M. 1995. Basal forebrain cholinergic lesions disrupt increments but not decrements in conditioned stimulus processing. J Neurosci 15: 7315-7322.

Corbit LH, Balleine BW. 2005. Double dissociation of basolateral and central amygdala lesions on the general and outcome-specific forms of Pavlovian-instrumental transfer. J Neurosci 25: 962-970.

Davis M. 2000. The role of the amygdala in conditioned and unconditioned fear and anxiety. In The amygdala, 2nd ed. (ed. JP Aggleton), pp. 213-287. Oxford UP, New York.
El-Amamy H, Holland PC. 2006. Substantia nigra pars compacta is critical to both the acquisition and expression of learned orienting of rats. Eur J Neurosci 24: 270-276.

Everitt BJ, Ccardinal RN, Parkinson JA, Robbins TW. 2003. Appetitive behavior: Impact of amygdala-dependent mechanisms of emotional learning. Ann NY Acad Sci 985: 233-250.

Fadel J, Deutch AY. 2002. Anatomical substrates of orexin-dopamine interactions: Lateral hypothalamic projections to the ventral tegmental area. Neuroscience 111: 379-387.

Freedman LJ, Cassell MD. 1994. Distribution of dopaminergic fibers in the central division of the extended amygdala of the rat. Brain Res 633: $243-252$

Fudge JL, Haber SN. 2000. The central nucleus of the amygdala projection to dopamine subpopulations in primates. Neuroscience 97: 479-494.

Gallagher M, Graham PW, Holland PC. 1990. The amygdala central nucleus and appetitive Pavlovian conditioning: Lesions impair one class of conditioned behavior. J Neurosci 10: 1906-1911.

Gonzales C, Chesselet MF. 1990. Amygdalonigral pathway: An anterograde study in the rat with Phaseolus vulgaris leucoagglutinin (PHA-L). J Comp Neurol 297: 182-200.

Han JS, McMahan RW, Holland P, Gallagher M. 1997. The role of an amygdalo-nigrostriatal pathway in associative learning. J Neurosci 17: 3913-3919.

Haney RZ, Calu DJ, Takahashi YK, Hughes BW, Schoenbaum G. 2010. Inactivation of the central but not the basolateral nucleus of the amygdala disrupts learning in response to overexpectation of reward. J Neurosci 30: 2911-2917.

Hasue RH, Shammah-Lagnado SJ. 2002. Origin of the dopaminergic innervation of the central extended amygdala and accumbens shell: A combined retrograde tracing and immunohistochemical study in the rat. I Comp Neurol 454: 15-33.

Holland PC. 1977. Conditioned stimulus as a determinant of the form of the Pavlovian conditioned response. J Exp Psychol Anim Behav Process 3: 77-104.

Holland PC. 1984. The origins of Pavlovian conditioned behavior. In The psychology of learning and motivation (ed. G Bower), pp. 129-173. Prentice-Hall, Englewood Cliffs, NJ.

Holland PC. 2006. Enhanced conditioning produced by surprising increases in reinforcer value are unaffected by lesions of the amygdala central nucleus. Neurobiol Learn Mem 85: 30-35.

Holland PC, Gallagher M. 1993a. Effects of amygdala central nucleus lesions on blocking and unblocking. Behav Neurosci 107: 235-245.

Holland PC, Gallagher M. 1993b. Amygdala central nucleus lesions disrupt increments, but not decrements, in conditioned stimulus processing. Behav Neurosci 107: 246-253.

Holland PC, Gallagher M. 1999. Amygdala circuitry in attentional and representational processes. Trends Cogn Sci 3: 65-73.

Holland PC, Gallagher M. 2003. Double dissociation of the effects of lesions of basolateral and central amgydala on conditioned stimulus-potentiated feeding and Pavlovian-instrumental transfer. Eur J Neurosci 17: 1680-1694.

Holland PC, Kenmuir C. 2005. Variations in unconditioned stimulus processing in unblocking. J Exp Psychol Anim Behav Process 31: $155-171$.

Holland PC, Gallagher M. 2006. Different roles for amygdala central nucleus and substantia innominata in the surprise-induced enhancement of learning. J Neurosci 26: 3791-3797.

Holland PC, Maddux JM. 2010. Brain systems of attention in associative learning. In Attention and learning (ed. CJ Mitchell, ME LePelley). Oxford University Press, Oxford, UK (in press).

Holland PC, Chik Y, Zhang Q. 2001. Inhibitory learning tests of conditioned stimulus associability in rats with lesions of the amygdala central nucleus. Behav Neurosci 115: 1154-1158.

Hunt PS, Campbell BA. 1997. Autonomic and behavioral correlates of appetitive conditioning in rats. Behav Neurosci 111: 494-502.

Jia HG, Rao ZR, Shi JW. 1997. Evidence of gamma-aminobutyric acidergic control over the catecholaminergic projection from the medulla oblongata to the central nucleus of the amygdala. J Comp Neurol 381: 262-281.

Kapp BS, Frysinger RC, Gallagher M, Haselton JR. 1979. Amygdala central nucleus lesions: Effect on heart rate conditioning in the rabbit. Physiol Behav 23: 1109-1117.

Kaufling J, Veinante P, Pawlowski SA, Freund-Mercier MJ, Barrot M. 2009. Afferents to the GABAergic tail of the ventral tegmental area in the rat. J Comp Neurol 513: 597-621.

Lee HJ, Groshek F, Petrovich GD, Cantalini JP, Gallagher M, Holland PC. 2005. Role of amygdalo-nigral circuitry in conditioning of a visual stimulus paired with food. J Neurosci 25: 3881-3888.

Lee HJ, Gallagher M, Holland PC. 2006. The role of central amygdala connections to different mibrain dopamine systems for conditioned stimulus processing. Soc Neurosci Abstr 749: 741. 
Lee HJ, Youn JM, Gallagher M, Holland PC. 2008. Temporally limited role of substantia nigra-central amygdala connections in surprise-induced enhancement of learning. Eur J Neurosci 27: 3043-3049.

Leinninger GM, Jo YH, Leshan RL, Louis GW, Yang H, Barrera JG, Wilson H, Opland DM, Faouzi MA, Gong Y, et al. 2009. Leptin acts via leptin receptor-expressing lateral hypothalamic neurons to modulate the mesolimbic dopamine system and suppress feeding. Cell Metab 10: $89-98$.

Matsumoto M, Hikosaka O. 2007. Lateral habenula as a source of negative reward signals in dopamine neurons. Nature 447: 1111-1115.

McDannald M, Kerfoot E, Gallagher M, Holland PC. 2004. Amygdala central nucleus function is necessary for learning but not expression of conditioned visual orienting. Eur J Neurosci 20: 240-248.

Parkinson JA, Robbins TW, Everitt BJ. 2000. Dissociable roles of the central and basolateral amygdala in appetitive emotional learning. Eur $J$ Neurosci 12: $405-413$.

Pearce JM, Hall G. 1980. A model for Pavlovian learning: Variations in the effectiveness of conditioned but not of unconditioned stimuli. Psychol Rev 87: 532-552.

Pitkanen A, Amaral DG. 1994. The distribution of GABAergic cells, fibers, and terminals in the monkey amygdaloid complex: An immunohistochemical and in situ hybridization study. J Neurosci 14: 2200-2224.

Rescorla RA, Holland PC. 1982. Behavioral studies of associative learning in animals. Annu Rev Psychol 33: 265-308.

Robledo P, Robbins TW, Everitt BJ. 1996. Effects of excitotoxic lesions of the central amygdaloid nucleus on the potentiation of reward-related stimulu by intra-accumbens amphetamine. Behav Neurosci 110: 981-990.

Sagar SM, Sharp FR, Curran T. 1988. Expression of c-fos protein in brain: Metabolic mapping at the cellular level. Science 240: 1328-1331.
Saha S, Batten TF, Henderson Z. 2000. A GABAergic projection from the central nucleus of the amygdala to the nucleus of the solitary tract: A combined anterograde tracing and electron microscopic immunohistochemical study. Neuroscience 99: 613-626.

Schultz W, Dayan P, Montague PR. 1997. A neural substrate of prediction and reward. Science 275: 1593-1599.

Swanson LW. 1982. The projections of the ventral tegmental area and adjacent regions: A combined fluorescent retrograde tracer and immunofluorescence study in the rat. Brain Res Bull 9: 321-353.

Swanson LW. 1992. Brain maps: Structure of the rat brain. Elsevier, Amsterdam.

Swanson LW, Petrovich GD. 1998. What is the amygdala? Trends Neurosci 21: 323-331.

von Bohlen Und Halbach O. 2005. Modeling neurodegenerative diseases in vivo review. Neurodegener Dis 2: 313-320.

Wagner AR. 1978. Expectancies and the priming of STM. In Cognitive processes in animal behavior (ed. SH Hulse, H Fowler, WK Honig), pp. 177-209. Erlbaum, Hillsdale, NJ.

Wallace DM, Magnuson DJ, Gray TS. 1992. Organization of amygdaloid projections to brainstem dopaminergic, noradrenergic, and adrenergic cell groups in the rat. Brain Res Bull 28: $447-454$.

Wilson P, Boumphrey P, Pearce JM. 1992. Restoration of the orienting response to a light by a change in its accuracy. QJ Exp Psychol 44B: $17-36$.

Zahm DS, Jensen SL, Williams ES, Martin JR III. 1999. Direct comparison of projections from the central amygdaloid region and nucleus accumbens shell. Eur J Neurosci 11: 1119-1126.

Received April 29, 2010; accepted in revised form July 27, 2010. 


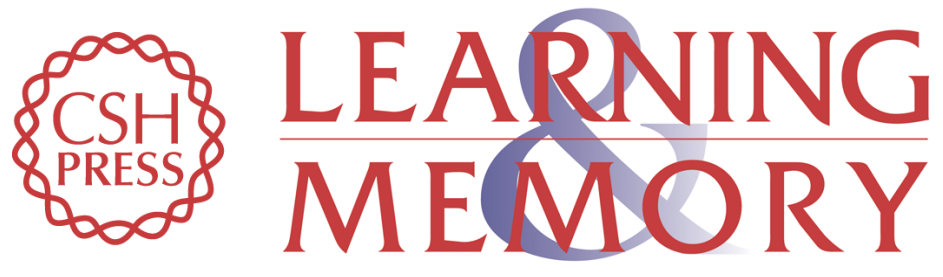

\section{The central amygdala projection to the substantia nigra reflects prediction error information in appetitive conditioning}

Hongjoo J. Lee, Michela Gallagher and Peter C. Holland

Learn. Mem. 2010, 17:

Access the most recent version at doi:10.1101//m.1889510

References This article cites 51 articles, 11 of which can be accessed free at: http://learnmem.cshlp.org/content/17/10/531.full.html\#ref-list-1

License

Email Alerting Receive free email alerts when new articles cite this article - sign up in the box at the Service top right corner of the article or click here. 